\title{
Removal of boron and arsenic from petrochemical wastewater using zeolite as adsorbent
}

\begin{abstract}
Petrochemical wastewater is one of the major industrial concerns due to the toxicity of heavy metals such as boron and arsenic. These metals must be progressively treated before discharged into receiving water. In this research, adsorption of boron and arsenic was conducted using natural zeolite (clinoptilolite). The arsenic and boron removal efficiencies using natural zeolite as adsorbents are 66 and $52 \%$, respectively, at its optimum conditions ( $\mathrm{pH} 8$, contact time $240 \mathrm{~min}$ and adsorbent dosage $480 \mathrm{~g} / \mathrm{L}$ ). Compared to various adsorbents, the adsorption using natural zeolite showed excellent boron and arsenic removal, thus has a great potential to be applied in industrial wastewater treatment plant.
\end{abstract}

Keyword: Zeolite; Adsorbent; Wastewater; Heavy metal adsorption 